\title{
MODULAR MINDS AND INPUT IN SECOND LANGUAGE ACQUISITION
}

\author{
Cecile le Roux \\ Department of General Linguistics, University of Stellenbosch
}

\section{Introduction}

The aim of this paper is twofold:

i. firstly, to show why second language learners (from perhaps as early as age six, but certainly after age (welve or thereabouts) are claimed to require instruction in addition to communicative exposure to the language; and

ii. secondly, to dispel the idea that, as long as theories of how second languages are acquired keep changing, no insight into the acquisition process can be gained from them.

The focus will be on theories of $\mathrm{L} 2$ acquisition that have a strong linguistic base to the exclusion of, for example, psychological process-based theories. By narrowing the focus of the paper, I hope to keep the main thrust of the argument clear. The choice of focus should not be taken to imply that other approaches have not provided useful perspectives on aspects of $L 2$ acquisition.

\section{Background}

The phenomenon of second language (L2) acquisition is often portrayed by means of the simple visual metaphor shown in (1): ${ }^{1}$

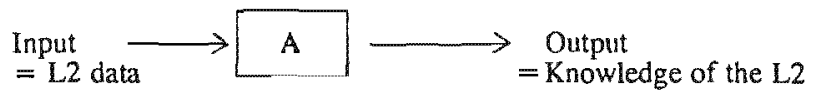

The block labelled "A" represents what, for the moment, I shall refer to as an "acquisition device". The activation of this device by encountered samples of the L2, i.e. the input, is assumed to result in knowledge of the L2. (Throughout this paper the term "knowledge of the $L 2$ " must be taken to refer only to knowledge of grammar. The term " $L 2$ " will be used to refer to any language acquired by someone who already knows at least one other language.) 
This portrayal of $\mathrm{L} 2$ acquisition closely resembles that given of first language (L1) acquisition in the sixties and seventies by linguists working within the framework of generative grammar. The latter portrayal can be schematized as in (2):

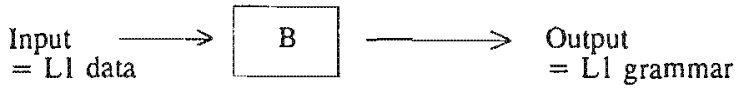

The device labelled " $\mathrm{B}$ " in (2) was assumed at the time to include at least a set of fundamental linguistic principles whose task it was to limit the possible forms that the grammar acquired by the child could take. This system of principles was termed Universal Grammar (UG). Apart from prior linguistic knowledge in the form of $U G$, the box $B$ was assumed also to contain a learning mechanism. The learning mechanism proposed by Chomsky (1965) took the form of an evaluation measure. The task of the evaluation measure was to determine which of the possible alternative grammars best fitted the data. Most $\mathrm{LI}$ acquisition researchers, however, assumed hypothesis testing to be the means by which the child in fact constructed a grammar, or "learnt" the language. The box $\mathrm{B}$ and all it contained became known as the Language Acquisition Device, or LAD for short.

The argument for the assumption that $\mathrm{Ll}$ acquisition is mediated by $U \mathrm{U}$ is based on the mismatch between what goes into the LAD and what comes out. It is argued that there is no way in which the child could construct the conplex system of rules and principles taken to constitute adult grammars on the basis of the kind of linguistic evidence, or input, children are normally exposed to. This input, it is claimed, is degenerate, i.e. not always fully grammatical. Moreover, it contains no negative evidence, i.e. information about what is not possible in the language being acquired. And, lastly, it generally underdetermines the final grammar, i.e. the acquired grammar goes far beyond the input. ${ }^{2}$ The argument for UG that proceeds from the degeneracy of the input has come to be known as the poverty-of-thestimulus argument.

The view of $\mathrm{Ll}$ acquisition represented in (2) is essentially a mentalist one. The LAD is claimed to be a mental device and the knowledge, or grammar, of the language that results from acquisition is taken to be a mentally represented system of categories, rules and constraints.

In the seventies the model proposed by generative grammarians for $\mathrm{Ll}$ acquisition was applied to $\mathrm{L} 2$ acquisition for the first time. ${ }^{3}$ This was the culmination of a number of developments in L2 research. First, there was the insight that the L2 learner, at any point in the acquisition process, in fact had internalized a grammar that was a system in its own 
right: what Selinker termed an "interlanguage". Second, there were the results of a vast number of studies, among them the so-called morpheme studies, which showed L2 acquisition to follow a developmental path similar to that of $\mathrm{L} 1$ acquisition. These findings formed the basis of Dulay and Burt's creative construction hypothesis. It was hypothesized that L2 learners construct rules on the basis of the linguistic data which they encounter, guided by a built-in mental structure which causes them to formulate certain types of hypotheses about the language being acquired. From here it was but a short step to the claim that there is no difference in essence between $L 1$ acquisition and $L 2$ acquisition: that the box labelled " $\mathrm{A}$ " in diagram (1) is nondistinct from the box labelled " $\mathrm{B}$ " in diagram (2).

\section{Krashen's Input Hypothesis}

The most explicit formulation of this claim came from Krashen whose account of L2 acquisition, known initially as the Monitor Model, and later as the Input Hypothesis, stirred a lot of attention and even more controversy in the late seventies and early eighties. ${ }^{4}$ The diagram (3) represents the salient aspects of Krashen's view of L2 acquisition:

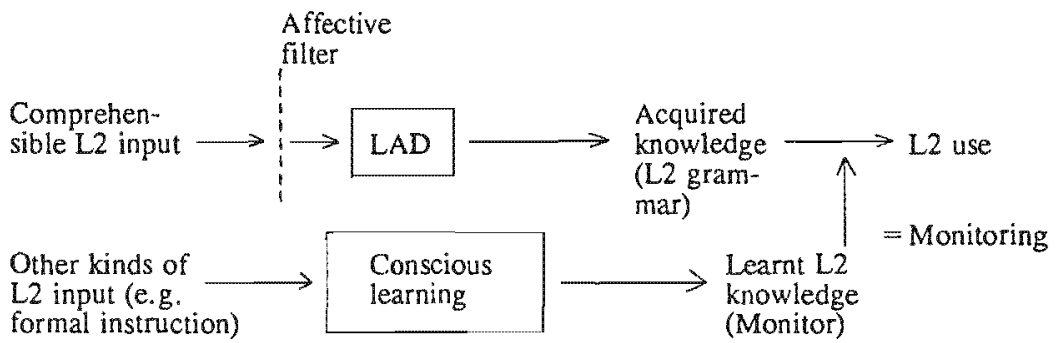

Briefly, Krashen claims that the L2 leamer, like the L1 learner, brings his or her natural language acquisition abilities, or LAD, to bear on samples of the L2 and, as a result, acquires knowledge of the L2. Features of the diagram in (3) that set it apart from the diagrams (1) and (2) above reflect Krashen's hypotheses about the factors responsible for the different levels of success achieved by $\mathrm{Ll}$ and L2 learners, on the one hand, and by younger and older L2 learners on the other hand. The affective filter comprises a variety of social, psychological and affective factors such as anxiety, lack of integrative motivation, lack of self-confidence, etc. that are claimed to constitute a "mental block" in L2 learners, particularly older ones. The filter inhibits acquisition by preventing input from reaching the LAD. The monitor is the product of a second type of phenomenon, which Krashen calls L2 leaming. Unlike acquired knowledge, learnt knowledge is gained through conscious learning that takes place when the learner is focusing on the form rather than the meaning 
of the message. Learnt knowledge comes into play only as a monitor, or check, on the way in which acquired knowledge is implemented in real-time language use.

Despite its flaws, Krashen's theory played its part in advancing the field of $L 2$ acquisition research. ${ }^{5}$ Two, related, aspects of his account of $L 2$ acquisition in particular interest us. The first is his emphasis on the role of input in L2 acquisition. (Although, as he (1985:vii) himself points out, he was not the inventor of the Input Hypothesis, he was the first to describe its role within a generative view of L2 acquisition.) The second is his distinction between acquired and learnt knowledge. Not only does Krashen distinguish between acquired knowledge, i.e. knowledge of language, and learnt knowledge, i.e. knowledge about language, but he claims that there is no interface between the two: leamt knowledge cannot become acquired knowledge. Also, the two kinds of knowledge result from different kinds of input. These features of Krashen's theory represent a significant advance in $L 2$ theorizing.

Prior to Krashen, $L 2$ acquisition research focused almost exclusively on the output of the acquisition process: that is, learner grammars or "interlanguages". The prime concern, following the proposal of the hypothesis that learner language is the product of interim grammars, or rule systems, was to formulate interlanguage rules and to establish sequences of acquisition on the basis of observed features of learners' speech. After Krashen, research on the properties and role of the input that L2 learners are exposed to became an important focus in L2 acquisition research. Krashen claimed that for acquisition to occur, the L2 leamer must receive messages which satisfy two criteria: (i) they must be comprehensible, in the sense that their meaning can be understood given the linguistic and nonlinguistic context, and (ii) they must contain unacquired structures that are beyond the leamer's current state of knowledge, i.e. at the next level in the natural sequence of acquisition.

Krashen himself has not described a natural sequence of acquisition that could support the proposed link with comprehensible input. He has also not indicated how the learner's current state of knowledge is to be determined in order that the correct kind of input may be provided. And, lastly, his failure to spell out what the learner's prior knowledge, i.e. the $L A D$, consists of, means that he has nothing to say about how the input interacts with whatever the learner already knows, to bring about a change in that knowledge. That is, Krashen does not tell us if and how new input interacts with $\mathrm{UG}$, knowledge of the $\mathrm{LI}$ and the leamer's current (approximative) knowledge of the L2. 6

What is important, however, is that by aligning his views on L2 acquisition with what 1 shall refer to as the UG-based view of LI acquisition, i.e. the view represented in diagram 
(2) above, Krashen ensured that the challenge of giving content to the notion 'comprehensible input' would be taken up. To understand subsequent proposals made about the properties and role of input within UG-related theories of L2 acquisition, we need to look briefly at certain key developments within the theory of UG itself, and within its related theory of $\mathrm{Ll}$ acquisition.

\section{White's parmmeter-setting view}

More or less at the time when Krashen was articulating his ideas, a major shift occurred in the way the box $\mathrm{B}$ in (2) above was conceptualised within UG theory. The Universal Grammar representing the child's prior linguistic knowledge, or initial state, came to be seen as comprising a number of sub-systems of principles, each associated with one or more open parameters with variable settings. On this view, the principles and parameters of UG constitute the initial state of all human beings' knowledge of language. What happens in the course of L1 acquisition is that the values for the open parameters are fixed on the basis of features of the linguistic input which the child receives. To give a simple example: it is assumed that UG contains a word order principle which states, roughly, that heads of phrases (for example verbs and nouns) occur in a fixed order with respect to their complements. The two possible orders, head-complement or complement-head, constitute the possible values of the parameter associated with the word order principle. The child needs only to determine on the basis of the evidence, or input, she is exposed to what the value of the parameter is for that language.

Once the values of all the parameters have been fixed, the child is said to have acquired the grammar of a specific language: the child's knowledge of language has attained its mature, or steady, state. This view of LI acquisition is schematically represented in the diagram (4):

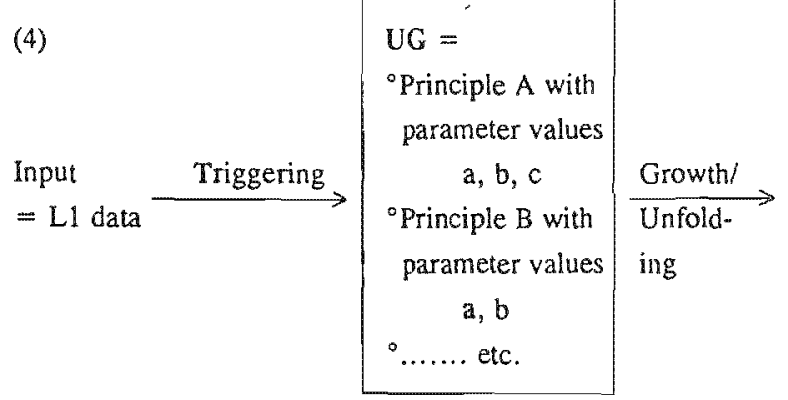

Grammar of L1 $=$

- Language-specific instantiation of A with parameter setting $\mathrm{C}$ - Language-specific instantiation of $B$ with parameter setting a $\circ$...... etc. 
The development of knowledge of a language is no longer seen as the piecemeal discovery of the rules of the language through processes such as hypothesis formation and testing. Instead of rules being leant, values or settings for pre-existing parameters are assumed to be activated, or "triggered", by the linguistic input. ${ }^{7}$ Given that an adequate range of utterances in the target language is encountered, the appropriate values are automatically assigned to the parameters. Thus, knowledge of the $\mathrm{Ll}$ unfolds or grows, to use some of the terms that are employed to describe $\mathrm{Ll}$ acquisition. ${ }^{8}$ Not all aspects of the LI are acquired in this way, of course: only the core grammatical features that are languagespecific instantiations of universal principles and parameters. Specifically, the lexical items (or the words) of the language have to be learnt along with their meanings and quite detailed information concerning the kinds of sentence structures they will fit into. Idioms, along with other less usual constructions and, of course, all the social and cultural conventions relating to the use of the language have to be learnt.

With this background, let us return to $\mathrm{L} 2$ acquisition. In the mid-eighties, in a detailed review of Krashen's proposals, Lydia White (1987) gives Krashen credit for drawing attention to the important role that input has to play in the L2 learner's progression from one stage to the next. What is important, however, is that she shows how it is possible to make much more precise claims about what constitutes appropriate input in L2 acquisition (i) by adopting the principles-and-parameters theory of UG, and (ii) by taking into account the fact that the L2 learner already knows at least one language. On this view, L2 acquisition can be schematically represented as follows:

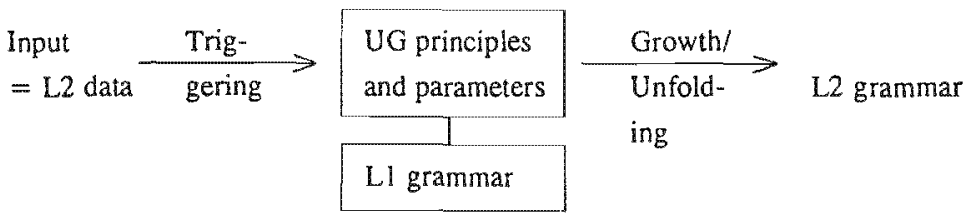

What claims does this view of L2 acquisition make about the kind of input that $\mathrm{L} 2$ learners need? It is clear that L2 learners differ from L1 learners in a crucial way: in the case of L2 acquisition, the parameters associated with the principles of UG have already had values assigned to them. For example, the word order parameter will already have been set to either the value head-complement, or the value complement-head for the L1. L2 learners therefore need evidence on the basis of which parameter values can be changed. ${ }^{9}$ However, the necessary evidence is not always available in naturally occurring samples of the L2 encountered by the learner. 
White (1987:100-107) describes two kinds of circumstances in which naturalistic L2 input will not provide the evidence necessary to trigger the resetting of a parameter. The first is the situation where the bulk of the input received by the leamer consists in utterances produced by other L2 leamers. White $(1987: 101)$ cites the example of native speakers of Spanish leaming English. Spanish is a so-called pro-drop language, that is, a language in which subject pronouns can be omitted. So, for instance, He speaks in English can be translated as Parla in Spanish, and It's raining as Plove. Now, native speakers of Spanish learning English are known to omit subject pronouns in English as well. This means, of course, that much of the input received by someone learning English with them, although it will no doubt be comprehensible, will lack precisely the evidence necessary to cause a change in the value of the pro-drop parameter from the LI (Spanish) setting to the L2 (English) setting. 10

The second type of situation in which naturalistic $L 2$ input will be inadequate, according to White (1987:103), is one in which even native speaker utterances cannot provide the evidence necessary to cause a change in the value of an Lll parameter. This is typically the case when the learner needs negative evidence, i.e. evidence that something is not possible, in order to arrive at the correct parameter setting for the language being learnt. Consider the case of a native speaker of French learning English. In French, adverbs may appear between a verb and its direct object, as in (6a), whereas in English they may not, as shown in $(6 \mathrm{~b})$ :
(a) Jean $a$ bu
LENTEMENT SON
café. Jean has drunk slowly his coffee.

(b) *John drank SLOWLY his coffee.

A native speaker of English learning French needs only to hear sentences such as (6a), i.e. needs only positive evidence in the form of occurring sentences, to realize that French differs from English in allowing adverbs between the verb and the direct object. A native speaker of French learning English, by contrast, needs nonoccurring sentences such as (6b), or negative evidence, to tell him or her that it is not possible in English to place adverbs between a verb and its direct object. And, of course, nonoccurring sentences such as (6b), by their very nature, will always be absent from the input which the learner receives. The input that the learner receives may contain sentences such as those in (7):

(7) (a) John drank his coffee SLOWLY.

(b) John SLOWLY drank his coffec. 
(c) SLOWLY, John drank his coffee.

(d) John is SLOWLY drinking his coffee.

From the occurrence of such sentences in the input the learner can justifiably conclude that adverb placement is relatively free in English. Sentences such as (6b) could be absent from the input for purely accidental reasons. The learner has no way of knowing that the gap is systematic rather than accidental. Moreover, learners do not look out for nonoccurring forms, or gaps, in the input in the first place.

The important point is that, with a more clearly articulated theory of the nature of (i) the learner's prior linguistic knowledge, (ii) the learner's acquired (L1) knowledge, and (iii) the way in which input interacts with these two kinds of knowledge, an important difference between $\mathrm{L} 1$ acquisition and $\mathrm{L} 2$ acquisition emerges; a difference not provided for by Krasher. Unlike L1 acquisition, L2 acquisition is not guaranteed, given only a sufficiently wide range of naturalistic input and a low affective filter, as Krashen proposes. In addition to positive evidence (Krashen's "comprehensible input"), the L2 learner also needs negative evidence. That is, the $\mathrm{L} 2$ learner needs evidence about certain differences between the $\mathrm{L} 1$ and the L2 which, in the normal course of events, would not be manifest in naturally occurring samples of the L2.

So, by the mid-eighties, UG-based L2 acquisition research had reached a point where it was no longer necessary to assume, as Krashen had, that there was not much anyone could do to facilitate a learner's acquisition of the L2, other than to ensure that the learner is exposed to comprehensible utterances in the $\mathrm{L} 2$ and that his or her affective filter is low. It was no longer necessary to accept that manipulation of the input is fruitless because one cannot know what the learner's current state of knowledge is, nor what type of input is required to change this state. Rather, it had become possible to make quite precise claims about the learner's initial state of mind given the principles-and-parameters theory of LI knowledge and acquisition. And, assuming that the learner embarked on the task of acquiring the L2 with the principles of UG still intact, but with parameter values set for the L1, it was now possible to make precise claims about the kind of input that the learner would require in order to reset the parameters to the correct $\mathrm{L} 2$ values. And the late eighties and early nineties indeed produced a spate of empirical studies investigating precisely such claims. ${ }^{11}$

A question which arises, if one accepts Krashen's distinction between acquired and learnt knowledge, is whether the L2 knowledge gained through negative evidence is indeed acquired (hence can form the basis of spontaneous performance in the L2), or whether it can merely serve as a monitor during actual language use. This question brings us to the 
second aspect of Krashen's accoun of L2 acquisition that was mentioned earlier as having led to an advance in $\mathrm{L} 2$ acquisition research. The first, it will be recalled, was his emphasis on the role of input in L2 acquisition, which was dealt with in paragraph 2 above.

\section{Modular minds: a dilemua for $\mathrm{L} 2$ acquisition theory}

Krashen's division of linguistic knowledge into acquired and learnt knowledge reflects a modular view of the human mind and, more specifically, the view that knowledge of language is an autonomous cognitive module, i.e. a highly independent cognitive system distinct from, say, perceptual systems, or our system of real-world knowledge and beliefs, or our general problem-solving system, etc. ${ }^{12}$ To say that knowledge of language is an autonomous cognitive module, is to say, among other things, (i) that it is organised in terms of principles that are unique to it, and which it does not share with any other cognitive system, and (ii) that it can process only information of a certain kind. The latter property entails, crucially, that what $I$ shall refer to as the language module can pass on information to other cognitive systems, but cannot itself make use of any information which it is not specifically designed to process. Language use, on this view, is taken to be a complex phenomenon resulting from the processing, by a so-called central processor, of information produced not only by the language module, but also by a variety of other cognitive modules and systems. The diagram in (8) is a highly simplified graphic representation of what a modular view of language use entails.

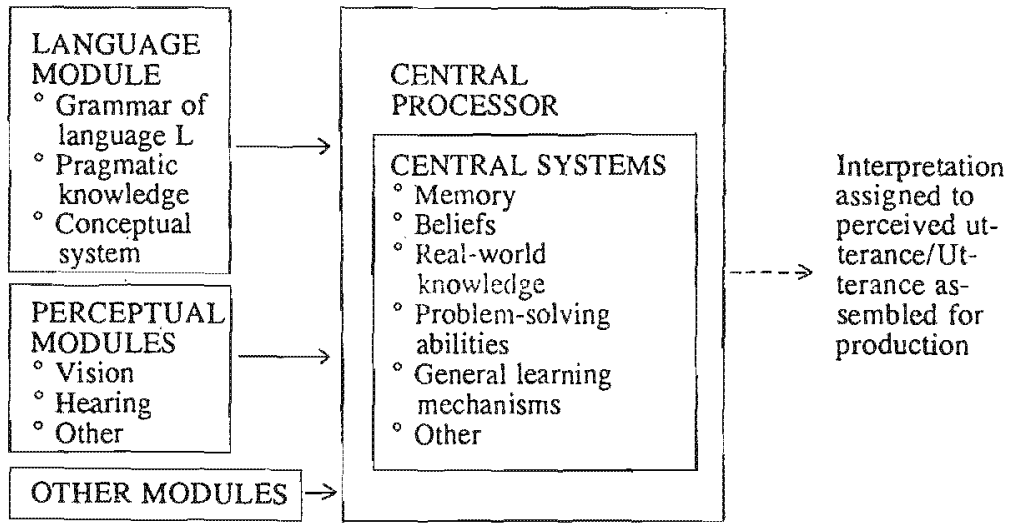

Adapted from (White 1989:178)

Translated into the terms used by proponents of a modular view of the mind, what Krashen calls "acquired knowledge" is part of the language module. What he terms "learnt 
knowledge" is situated in the central systems. As the central systems have access to information produced by cognitive modules such as the language module, but not the other way round, learnt knowledge is not available as input to the language module. Learnt knowledge can only be accessed by the central processor in actual language use.

The hypothesis that language constitutes a separate and unique mental capacity has been a distinguishing feature of accounts given of $\mathrm{Ll}$ acquisition and use within generative linguistic theory from its earliest formulations. ${ }^{13}$ However, the question of the relationship between acquired and learnt knowledge was not seriously considered in the context of L2 acquisition before Krashen proposed his Monitor Hypothesis. Since then, interesting questions have been raised about the role of the language module in L2 acquisition.

Krashen's claim that consciously learnt knowledge remains distinct from unconsciously acouired knowledge is consonant with the view that knowledge of language constitutes a separate cognitive module. But what are we to make of White's more recent claim about the necessity of negative evidence in L2 acquisition? The function of negative evidence (i.e. information about the nonoccurrence of certain forms in the L2), is to enable the learner to reset parameters associated with linguistic principles to their correct $L 2$ values. The problem is that parameter values are part of knowledge of language, i.e. of the language module. The language module cannot access information or feedback from other cognitive systems. Learnt knowledge, such as the knowledge gained on the basis of negative evidence is metalinguistic in nature, i.e. it is knowledge about language. As such, it is computed and stored in the central processing systems. Therefore learnt knowledge should not be able to bring about a change in parameter settings. 14

It is interesting to note, in this regard, the results of a study conducted by White (1991) to determine the effectiveness of teaching adverb placement to a group of 11 and 12 year-old French-speaking learners of English. The positive funding of this study was that only the experimental group who had been exposed to negative evidence specifically focused on adverb placcment came to know that adverbs may not interrupt the verb and its object in English. The control group, who had received only naturalistic input (i.e. utterances unaccompanied by comments about their form or status) were unable to deduce the impossibility of the verb-adverb-object order in English. The negative finding of this study, however, was that results from a follow-up study conducted with the experimental group one year later showed that the structured classroom input did not have lasting effects: the learners had reverted to using the incorrect orders. In other words, the provision of negative evidence had not resulted in a change in the learners' interlanguage grammars. It had been 
learnt knowledge, or knowledge about English; not acquired knowledge, or knowledge of English. 15

This, then, is the dilemma that UG-related theories of $L 2$ acquisition faced at the beginning of the nineties. On the one hand, if language is indeed an autonomous cognitive module, then Krashen is right: learnt knowledge cannot become acquired knowledge. On the other hand, if certain properties of L2 grammars cannot be deduced on the basis of naturally occurring samples of the language alone, then White is right: learners need to receive negative evidence. Negative evidence, however, results in learnt knowledge. So, if both these positions are maintained, we are forced to conclude that aspects of the L2 are unacquirable. 16

\section{A way out of the dilemma? 'Noticing' and 'mimicking'}

Two lines of response to this conclusion have emerged in the recent literature. I shall deal very briefly with both. The first response accepts the conclusion that only part of the L2 grammar can be acquired via the language module on the basis of naturally occurring language samples alone and that the remaining properties of the $\mathrm{L} 2$ must be learned. It hypothesizes, however, that there must be some, yet to be discovered, mechanism whereby learnt knowledge can eventually be translated into acquired knowledge. The challenge, then, is to discover the nature of this mechanism.

A mechanism which has been proposed to mediate between learnt knowledge and acquisition is noticing. With "noticing" is meant that the learner, on the basis of specially constructed input, is sensitized to some feature of the L2. Once the leamer is sensitive to a particular feature of the $\mathrm{L2}$, this feature becomes "noticeable" to the language module. That is, whenever the feature occurs in subsequent samples of the language that the learner encountcrs, it can be processed by the language module so as to become acquired knowledge. ${ }^{17}$ This subsequent input can take the form of utterances produced by other speakers, or it can be self-generated, that is produced by the learner. ${ }^{18}$ The process whereby the leamer is sensitized to the targeted feature of the L2 has become known as "input enhancement" (also known formerly as "consciousness raising"). Enhancement of the input to the learner entails carefully selecting the linguistic property to be focused on and then making the property salient in some way. Linguistic properties can be made salient either positively, i.e. by pointing out and commenting on correct occurrences of the property in question, or negatively, by pointing out the nonoccurrence of the property in question via correction or other means. 
What distinguishes input enhancement from traditional grammar instruction is the underlying assumption that the knowledge resulting from the provision of enhanced input cannot lead directly to a change in the learner's grammar, or acquired knowledge. All it can do directly is to induce sensitivity. Sensitivity must in some, yet to be specified, way lead to noticing; and noticing, it is claimed, can lead to acquisition.

This first line of response tackles the one horn of the dilemma outlined in paragraph 4 above, viz. the supposed lack of an interface between the language module and central cognitive systems. The second line of response tackles the other horn of the dilemma, viz. the claim that L2 leamers require negative evidence to reset parameters which cannot be reset to their $\mathrm{L} 2$ values on the basis of naturally occurring samples of the $\mathrm{L} 2$ alone. The response is to deny the assumption underlying this claim, viz. the assumption that parameiers (any parameters) can be reset in the course of L2 acquisition. Once parameters have been sel for the Ll, it is argued, all that remains accessible to the L2 learner are the principles of UG and the $\mathrm{LI}$ parameter settings. Parameter values not triggered in the course of Ll acquisition are irretrievably lost. L2 acquisition, in terms of this response, involves UG principles, but not the parameters associated with these principles. And if parameters are not involved, the negative evidence question simply does not arise.

Where L2 learners do appear to have reset one or more parameters to the correct L2 values, this is claimed to be the result of "mimicking". That is, L2 learners make use of devices (i.e. categories and principles) made available by $U G$, in conjunction with $\mathrm{L} 1$ parameter settings, to construct a mental grammar that fits the naturally occurring $L 2$ data, i.e. the positive evidence, which they encounter. This grammar allows the leamer to "mimic" some of the surface patterns of the L2, i.e. to appear like a native speaker on some constructions. The learner's grammar is fundamentally different from native L2 grammars, however. ${ }^{19}$

The concepts of 'noticing' and 'mimicking' are still vague and undefined and the claims involving them raise many questions. For example, it is not clear whether noticing is supposed to be conscious or unconscious, nor how it is related to triggering, the highly automatic and obligatory mechanism assumed to mediate between naturalistic input and the language module in acquisition. Neither is it clear how noticing solves White's problem: nonoccurring forms in the L2 will still not be available in utterances produced on the basis of learnt knowledge. It is not clear, therefore, how their nonoccurrence is to be noticed.

As regards 'mimicking', the question arises what kind of acquisitional mechanism it represents. Is it a triggering mechanism, which is the only type of mechanism claimed to be involved in acquisition on UG-based theories of $L 2$ acquisition? $O r$ is it a hypothesis- 
formation-and-testing mechanism, which is the type of mechanism assumed to be involved in leaming? If it is a triggering mechanism, what is it that gets triggered if not parameter settings? If it is a hypothesis-formation-and-testing mechanism, how does it resolve the learning-versus-acquisition problem described in paragraph 4 above? We do not yet have answers to any of these questions.

\section{Conclusion}

The many unanswered questions raised at the end of the previous section should not be seen as cause for despair. Take the concept of 'noticing', for example. The mere fact that it gives rise to new questions does not mean that it is a worthless concept. Proposals formulated in terms of this concept have indeed produced a wealth of experimental studies investigating the effects of various types of input enhancement within communication-based L2 learning environments: studies such as those conducted by Tomasello and Herron (1988), Van Patten (1990), Lightbown and Spada (1990), White, Spada, Lightbown and Ranta (1991), Doughty (1991), Fotos and Ellis (1991) and Carroll and Swain (1993), amongst others.

Studies such as these are interesting and useful for two reasons. Firstly, they provide $\mathrm{L2}$ language teachers with often quite innovative techniques for focusing on aspects of linguistic structure within the context of a communicative syllabus. Secondly, the results of these studies, too, will no doubt lead to the formulation of new hypotheses about the ways in which various types of linguistic input interact with the cognitive capacities which the L2 learner brings to bear on the acquisition task. These studies too will play their part in getting us to the point where, in Schachter's (1991:99) words,

we will have answers to the negative evidence question like 'Yes, under these circumstances with these aspects of language with these age groups', and 'No, under those circumstances with those aspects of language with those age groups'.

I hope to have demonstrated how each tentative answer to one of the many questions facing us provides us with another small but important piece of the second language acquisition puzzle. 
1. See e.g. White $1989: 5,37$ and Cook 1993:200, 205 for the schematic portrayal of first and second language acquisition presented in (1) and (2). See Chomsky 1964:61 for his original version of the schena in (2).

2. Cf. e.g. White 1989:5-15 for a full discussion and illustration of the degeneracy of input in $\mathrm{Ll}$ acquisition.

3. The following interpretation of developments in L2 acquisition research is based on the account given in, amongst others, (Ellis 1985) and (Cook 1993).

4. See Krashen 1985 for a firsthand account of his views, or Ellis 1985 and Cook 1993 for an interpretation and critical assessment.

5. Krashen's account of L2 acquisition has elicited fierce criticism and sparked bitter controversy. He has been accused of failing to spell out the nature of comprehensible input, of merely stating the obvious in the form of a quasi-scientific theory. His theory has been claimed to be circular: anything that leads to acquisition must be comprehensible input, so comprehensible input is whatever leads to acquisition. What is missing, according to his critics, is an independent specification of the linguistic forms that constitute comprehensible input of the kind that will lead to acquisition of an aspect of the L2 grammar. It has been argued that Krashen conflates comprehension (an aspect of language use) and acquisition. He has been criticised for claiming that acquisition depends only on understanding messages in the L2 and for according no role at all to either the learner's L1 knowledge, or to the L2 utterances produced by the learner. His noninterface hypothesis, the hypothesis that consciously learnt knowledge cannot convert into unconscious, acquired knowledge, has been rejected as being contrary to the available evidence. And, lastiy, he has been criticised for leaving the phenomenon of $\mathrm{L} 2$ acquisition as mysterious as ever by failing to spell out how comprehensible input is dealt with by the mind. He gave no indication of having an explicit theory about the internal structure of the LAD, although such a theory was available at the time. See e.g. McLaughlin 1987:ch. 2 for a detailed criticism of Krashen's view of L2 acquisition.

6. See White 1987 for elaboration of these points.

7. But, see Atkinson 1992:ch. 8 for an argument to the effect that there is in fact no qualitative difference between parameter-setting and hypothesis formation.

8. See Botha 1981:par. 2.4 for some discussion of the differences between the pre- and post-eighties UG theory of $\mathrm{LI}$ acquisition.

9. Note that it is assumed here that L2 learners start out by transferring the $\mathrm{L} 1$ parameter setting to the $\mathrm{L} 2$. This is not an uncontroversial assumption. Some researchers have claimed that parameters have default values and that both LI 
leamers and L2 learners start out by assuming the default values until they are forced by the evidence to abandon the assumption. Cf. e.g. Cook 1993:207 and White 1989:50 for some discussion of this point.

10. Precisely this situation arises in immersion classrooms, it is claimed, with exactly the results described here. Cf. e.g. Hammerly 1987.

11. See, e.g., White 1991, White et al. 1991, Trahey and White 1993 and Spada and Lightbown 1993, as well as other studies undertaken by Lydia White and the members of the L2 research group at McGill University. See also the contributions in Eubank (ed.) 1991 and the references in Cook 1993:chapters 8 and 9.

12. See Newmeyer 1983:2-3 and par. 1.4, and Botha 1989:par, 2.7.3-2.7.4 for discussion of the modular view of language. See also Fromkin 1993 for an overview of evidence (from studies of aphasics, brain-damaged children and so-called "idiots savants") for the autonomy of language.

13. The claim that knowledge of language constitutes a cognitive module is a more restrictive claim, as a system which is considered to be a cognitive module has certain clearly defined properties which sets it apart from cognitive systems that are taken to belong to the set of general cognitive systems (or central systems). Chomsky first explicitly referred to knowledge of language as "a module" in 1980.

14. See Schwartz and Gubala-Ryzak 1992 and Schwartz 1993 for this argument. According to Schwartz (1993:157ff) the crucial difference between primary linguistic data (i.e. utterances in the L2, which is the kind of input the language module can deal with) and negative evidence is that negative evidence typically takes the form of information about the L2 rather than just utterances in the L2. A typical example of negative evidence would be the statement that sentences such as ${ }^{*} J o h n$ drank slowly his coffee are not possible in English, which is a statement about the language. Knowing that a certain type of sentence is not possible in the language, hence, is propositional knowledge. Propositional knowledge is claimed not to constitute appropriate input for the language module. Therefore this knowledge can play no part in the grammar-building process: it cannot lead to a change in the learner's interlanguage grammar.

15. But see Lightbown and Pienemann's (1993) rebuttal of the conclusion that formfocused instruction (including the provision of negative evidence) cannot bring about developmental changes in the L2.

16. These properties can of course be leamed, i.e. become part of leamt linguistic knowledge. This raises the question of what implications, if any, the distinction between acquired and leamt knowledge has for the learner's L2 behaviour. Schwartz (1993:160) speculates that the distinction will show up in on-line oral production in 
the L2. Because of the heavy processing load during on-line production, access to items stored in long-term memory (i.e. learnt knowledge) may be inhibited.

17. See Fotos 1993 and Sharwood Smith 1993 for a detailed account and references to other proponents of this view of the role of noticing. See also Van Patten and Cadierno 1993 for what they call "processing instruction", i.e. explicit efforts to help learners notice some targeted feature of the input.

18. See e.g. Ellis 1993 and Swain 1993 for some discussion of the potential role of the leamer's own output in $L 2$ acquisition.

19. See, e.g., Hawkins, Towell and Bazergui 1993, Smith, Tsimpli and Ouhalla 1993 and the references cited there for this view. The fact that the L2 learner's grammar differs from that of L2 native speakers, according to Hawkins et al. (1993:221), may show up in nonnative-like behaviour on constructions other than those on the basis of which the grammar was constructed. 


\section{Bibliography}

Atkinson, M. 1992. Children's syntax. An introduction to principles and parameters theory. Oxford: Blackwell.

Botha, R.P. 1989. Challenging Chomsky. The Generative Garden Game. Oxford: Basil Blackwell.

Carroll, Suzanne and Merrill Swain. 1993. Explicit and implicit negative feedback. An empirical study of the learning of linguistic generalizations. Studies in Second Language Acquisition 15(3):357-386.

Chomsky, N. 1964. Current issues in linguistic theory. In Fodor, J.A. and J.J. Katz (eds.) The structure of language. Readings in the philosophy of language. Englewood Cliffs: Prentice.Hall Inc., 50-118.

Chomsky, N. 1965. Formal discussion: the development of grammar in child language. In Bellugi, $U$. and $\mathrm{R}$. Brown (eds.) The acquisition of language. Lafayette, Ind: Purdue University Press.

Cook, V. 1993. Linguistics and second language acquisition. Houndmills and London: Macmillan.

Doughty, Catherine. 1991. Second language instruction does make a difference. Evidence from an empirical study of SL relativization. Studies in Second Language Acquisition 13(4):431-469.

Ellis, R. 1985. Understanding second langwage acquisition. Oxford: Oxford University Press.

Ellis, R. 1993. The structural syllabus and second language acquisition. TESOL Quarerly 27(1):91-113.

Eubank, L. (ed.) 1991. Point counterpoint. Universal Granmar, in the second language. Amsterdam/Philadelphia: John Benjamins Publishing Company.

Fotos, Sandra S. 1993. Consciousness raising and noticing through focus on form: grammar task performance versus formal instruction. Applied Linguistics 14(4):385407. 
Fotos, Sandra and Rod Ellis. 1991. Communicating about grammar: a task-based approach. TESOL Quarterly 25(4):605-628.

Fromkin, Victoria A. 1993. What studies of the brain can tell us about language (if anything) and vice versa. Prodeedings of the nineteenth annual meeting of the Berkeley Linguistics Sociery: 143-158.

Hammerly, H. 1987. The immersion approach: litnus test of second language acquisition through classroom communication. Modern Language Journal 71:395-401.

Hawkins, R., R. Towell and N. Bazergui. 1993. Universal Grammar and the acquisition of French verb movement by native speakers of English. Second Language Research $9(3): 189-233$.

Krashen, S. 1985. The inpul hypothesis: issues and implications. London: Longman.

Lightbown, Patsy M. and Manfred Pienemann. 1993. Comments on Stephen D. Krashen's "Teaching issues: formal grammar instruction". TESOL Quarterly 27(4):717-722.

Lightbown, Patsy M. and Nina Spada. 1990. Focus-on-form and corrective feedback in communicative language teaching. Effects on second language learning. Studies in Second Language Acquisition 12(4):429-448.

McLaughlin, B. 1987. Theories of second-language learming. London: Edward Arnold.

Newmeyer, F.J. 1983. Grammatical theory. Its limits and its possibilities. Chicago and London: The University of Chicago Press.

Schachter, J. 1991. Corrective feedback in historical perspective. Second Language Research 7(2):89-102.

Schwartz, B.D. 1993. On explicit negative data effecting and affecting competence and linguistic behaviour. Siudies in Second Language Acquisition 15:147-163.

Schwartz, B.D. and M. Gubala-Ryzak. 1992. Learnability and grammar reorganization in L2A: against negative evidence causing the unlearning of verb movement. Second Language Research 8(1):1-38. 
Sharwood Smith, M. 1993. Input enhancement in instructed SLA. Theoretical bases. Studies in Second Language Acquisition 15:165-179.

Smith, N.V., I-M. Tsimpli and J. Ouhalla. 1993. Leaming the impossible: the acquisition of possible and impossible languages by a polyglot savant. Lingua 91:279-347.

Spada, N. and P.M. Lightbown. 1993. Instruction and the development of questions in 12 classrooms. Studies in Second Language Acquisition 15:205-224.

Swain, M. 1993. The Output Hypothesis: just speaking and writing aren"t enough. The Canadian Modern Language Review 50(1): 158-164.

Tomasello, M. and C. Herron. 1988. Down the garden path: inducing and correcting overgeneralization errors in the foreign language classroom." Applied Psycholinguistics 9:237-246.

Trahey, M. and L. White. 1993. Positive evidence and preemption in the second language classroom. Studies in Second Language Acquisition 15:181-204.

VanPatten, Bill. 1990. Attending to form and content in the input. An experiment in consciousness. Studies in Second Language Acquisition 12(3):287-299.

VanPatten, Bill and Teresa Cadierno. 1993. Explicit instruction and input processing. Studies in Second Language Acquisition 15:225-243.

White, L. 1987. Against comprehensible input: the Input Hypothesis and the development of second-language competence. Applied Linguistics 8:95-110.

White, L. 1989. Universal Grammar and second language acquisition. Amsterdam/Philadelphia: John Benjamins Publishing Company.

White, L. 1991. Adverb placement in second language acquisition: some effects of positive and negative evidence in the classroom. Second Language Research 7(2):133-161.

White, L., N. Spada, P.M. Lightbown and L. Ranta. 1991. Input enhancement and L2 question formation. Applied Linguistics 12(4):416-432. 